\title{
The Impact of Market Conditions on RN Staffing in Hospitals: Using Resource Dependence Theory and Information Uncertainty Perspective
}

This article was published in the following Dove Press journal: Risk Management and Healthcare Policy

\author{
Dong Yeong Shin' \\ Robert Weech-Maldonado ${ }^{2}$ \\ Jongwha Chang ${ }^{3}$ \\ 'Department of Public Health Sciences, \\ New Mexico State University, Las \\ Cruces, NM, USA; ${ }^{2}$ Department of \\ Health Services Administration, \\ University of Alabama, Birmingham, AL, \\ USA; ${ }^{3}$ Department of Pharmaceutical \\ Sciences., University of Texas, El Paso, \\ TX, USA
}

Correspondence: Jongwha Chang Department of Pharmaceutical Sciences, School of Pharmacy, University of Texas at El Paso, 500 W. University Ave, El Paso, TX 79968, USA

Tel + | 9|5-747-824|

Email jchang@utep.edu
Purpose: Due to a limited number of studies with generalizable findings on the relationships between market conditions and RN staffing levels in hospitals, this study examined such relationships employing a longitudinal design with a representative national sample.

Materials and Methods: We used longitudinal panel datasets from 2006 to 2010, drawn from various datasets including the American Hospital Association Annual Survey Database and the Area Health Resource File. A random-effects linear regression model was used to measure the influence of market conditions on RN staffing levels.

Results: The results of this study showed that market conditions were significantly associated with RN staffing levels in hospitals. First, an increase in per capita income and being located in urban rather than rural areas were associated with a greater number of RNs per 1,000 inpatient days and a higher ratio of RNs to LPNs and nursing aides. In addition, an increase in the number of physician specialists was associated with an increase in the number of RNs per 1,000 inpatient days. Second, an increase in Medicare HMO penetration in the environment was related to an increase in the RNs to LPNs and nursing aides ratio. Lastly, an increase in market competition was associated with an increase in the number RNs per 1,000 inpatient days and the ratio of RNs to LPNs and nursing aides.

Conclusion: The findings of this study suggest that staffing decision makers in hospitals should consider how to best align their RN staffing levels with their operating environment. In addition, health policy makers may improve the levels the RN supply in communities that needs more RNs by modulating external environmental forces (eg, specialist resources) that influence RN staffing levels in hospitals.

Keywords: market condition, external environment, munificence, dynamism, complexity, RN staffing, hospital

\section{Introduction}

One of the primary concerns of strategic management researchers lies in a better understanding of organizational decisions, actions, and processes that facilitate superior performance in organizations. ${ }^{1}$ Previous research argued that human resource practices in organizations were associated with their performance. ${ }^{2,3}$ Staffing is critical to an organization's performance because it is an instrument of acquiring, deploying, and retaining the talent required to execute its business strategies and perform well. ${ }^{4}$ Healthcare is a labor-intensive industry that is highly dependent on a skilled workforce. Given that delivery of patient care essentially involves the nursing workforce and that their labor costs represent a significant 
portion of hospitals' operating budgets, decisions concerning levels or patterns of nurse staffing are a crucial organizational activity that determines hospital performance to a large degree.

Some studies have long theorized about the influence of environmental conditions on organizational activities. ${ }^{5,6}$ For the healthcare industry, the significant relationship between the environment and organizational activities has been supported by empirical evidence. ${ }^{7-12}$ Blegen et al suggested that nurse staffing decisions in hospitals are in a relationship with environmental factors. ${ }^{13}$ Their perspectives illuminate the significance of market conditions on hospitals' staffing decision of crucial workforce who are in the center of health care delivery, such as registered nurses (RNs).

However, we found a limited number of studies have examined the relationship between market forces and nurse staffing in hospitals using a longitudinal design with a representative national sample. ${ }^{14,15}$ Given the relative paucity of research with generalizable findings, additional research is needed on the market conditions that may influence RN staffing levels to better understand how $\mathrm{RN}$ staffing in hospitals is shaped in given external environments. Using a panel data design with a national sample, this paper aims to contribute to knowledge by offering further generalizable evidence on the topic. A better understanding of how market conditions influence RN staffing levels will provide nurse managers and chief executive officers with the grounds to evaluate the appropriateness of their staffing plan in their specific external environmental context.

\section{Conceptual Framework}

This study investigated how RN staffing in hospitals is influenced by market conditions. To operationalize the market conditions, this study used the environmental uncertainty construct. Environmental uncertainty is a concept that has been widely explored in the organizational theory and strategic management literature. Because the external environment comprises all the factors outside organizations that are required to be considered in decision making, much attention has been paid to the fact that uncertainty in the external environment is an important consideration for firms during the strategic decisionmaking process. ${ }^{16,17}$ This study drew upon two dominant theoretical perspectives that conceptualize the environmental uncertainty construct. The first perspective, resource dependence theory, posits that the environment is a source of scarce and finite resources and that uncertainty arises as organizations compete with others to manage such resources. ${ }^{18,19}$ The second perspective is the information uncertainty perspective, which conceptualizes the environment as a source of information. ${ }^{16,19}$ It argues that uncertainty arises from a lack of perfect information regarding the environment. ${ }^{20}$ Prior to examining how the environmental uncertainty construct and the theoretical perspectives may inform the relationship between market conditions and RN staffing, we briefly introduce RN staffing measures used in this study below.

\section{RN Staffing}

Healthcare research uses various measurements of nurse staffing. Frequently used types of measures include fulltime equivalent (FTE) employment, nursing hours per patient day, share of registered nurses in total nursing staff, and nurse to patient ratios. ${ }^{21}$ This paper focuses on two measures of RN staffing: the number of RNs per 1,000 inpatient days and the ratio of RNs to licensed practical nurses (LPNs) and nursing aides. The number of RNs per 1,000 inpatient days indicates how a hospital intensively uses RN resources to provide a certain amount of patient care. This is one of the most frequently used measures of nurse staffing. ${ }^{22}$ The ratio of RNs to LPNs and nursing aides captures a hospital's staffing strategy by focusing on the retention of sufficient levels of the core nursing staff (ie, RNs). Among various measures of nurse staffing mix used in the literature, we used this ratio to gauge the level of replacement of RNs by less skilled or unlicensed nursing workforce (ie, LPNs and nursing aides) in hospitals.

The reason for using multiple measures of RN staffing is to capture potentially different staffing patterns or strategies in hospitals. Both the number of RNs per 1,000 inpatient days and the ratio of RNs to LPNs and nursing aides may indicate the levels of RN staffing in hospitals; however, they measure different aspects of RN staffing. For example, a hospital may have more RNs per 1,000 inpatient days, but a lower ratio of RNs to LPNs and nursing aides, than other hospitals if the focal hospital had proportionally more non-RN nursing workforce per 1,000 inpatient days than its counterparts. Accordingly, the number of RNs per 1,000 inpatient days or the ratio of RNs to LPNs and nursing aides may be measured differently, rather than consistently, depending on the levels of use of LPNs or nursing aides, which may influence healthcare quality and costs in hospitals. For brevity, throughout the paper, the number of RNs per 1,000 inpatient days and 
the ratio of RNs to LPNs and nursing aides may be referred to as the $\mathrm{RN}$ staffing intensity and $\mathrm{RN}$ to non$\mathrm{RN}$ ratio, respectively.

\section{Market Conditions}

As a result of integrating previous works rooted in two theoretical perspectives, three environmental uncertainty dimensions (ie, the environment uncertainty construct) were introduced: munificence, dynamism, and complexity. ${ }^{23}$ These environmental dimensions have been increasingly used in recent healthcare research to explore the relationship between environmental factors and hospital strategy. ${ }^{7-10}$

Munificence represents the degree of resource abundance in the environment. ${ }^{12,23}$ In resource dependence theory, when resources in the environment become scarcer, organizations face greater uncertainty and make strategic moves to either decrease their dependence on, or increase their control over, those resources for survival. ${ }^{6}$ Hospitals in less resourceful markets may consider a resource stringent strategy because a lack of resources may reduce input availability (eg, the supply of nurses and patients). By using fewer internal resources, hospitals may increase their production efficiency, which decreases their dependence on the reduced inputs resources in the environment. For example, when experiencing financial hardships due to decreases in patient admissions, hospitals may consider staff reductions to decrease capital costs for higher production efficiency.

In contrast, hospitals in more resourceful markets may select a resource-intensive strategy because higher levels of resources in the markets may be linked to higher degrees of inputs available to the operation of the hospitals. ${ }^{10}$ Zhao et al argued that ensuring a sufficient level of RN staffing is crucial for a better quality of patient care. ${ }^{15}$ Less skilled nursing personnel can provide many of the basics of patient care, but cannot replace RNs in more complex clinical care. ${ }^{15}$ RNs also play a critical role in the supervision of nursing workforce, communication with physicians, and overall patient care assessment and planning. ${ }^{24}$ In hospitals, proportionately more $\mathrm{RNs}$ and proportionately fewer LPNs in nursing staffs may represent nursing staffs of higher quality. ${ }^{25}$

Because staffing decisions involve balancing labor costs with the intensity of care needed for patients served by each hospital, if a hospital increases the number of $\mathrm{RNs}$, its total labor costs increase, and vice versa. ${ }^{13}$ In more resourceful markets, such as markets with more people who can afford higher quality services at higher costs, hospitals may attract such customers by providing higher quality services with sufficiently staffed RNs. Thus, this study postulates that hospitals operating in more munificent environments are more likely to have more RNs per service provided and proportionally more RNs than LPNs and nursing aides.

H1: Hospitals in more munificent markets will have a higher RN staffing intensity and a higher RN to non$\mathrm{RN}$ ratio than hospitals in less munificent markets.

Dynamism represents the rate of change and innovation in industries, and the uncertainty or predictability regarding the actions of competitors or customers. ${ }^{12,23,26}$ Dynamism is closely tied to the information uncertainty perspective. This perspective suggests that managers are unable to comprehend all the information in a given environment due to imperfect information and knowledge, and that such an inability is the primary cause of environmental uncertainty and impacts strategic decision-making in organizations. ${ }^{5,16,17}$ Research rooted in the information uncertainty perspective tends to focus on managerial perceptions of uncertainty about the environment, rather than on the objective state of the environment, such as resource availability. ${ }^{27}$ Dynamism is frequently measured by health maintenance organization (HMO) penetration because a strong presence of managed care in markets may lead hospital managers to perceive higher uncertainty on how to determine multiple rounds of contracting for risk. ${ }^{9,10,12}$

Higher HMO penetration in a market has a primary impact of reducing revenues available to hospitals. ${ }^{14}$ Resource dependence theory suggests that organizations have to increasingly accommodate the demand of environmental constituents to secure resources for survival as their dependency on key resource providers (eg, managed care organizations) increases. ${ }^{28}$ Because hospitals are highly dependent on the patient pools in managed care organizations (MCOs), they are more likely to search for a strategy to reduce internal costs for MCOs contracts as MCOs increase their market penetration. Since nurses' wages and benefits constitute a significant portion of the hospitals' operating budgets, hospitals may consider reducing labor costs by reducing the $\mathrm{RN}$ workforce in response to such revenue reductions. ${ }^{29}$ In summation, as the market becomes more dynamic, the number of the overall RNs and the ratio of RNs to LPNs and nursing aides are likely to decrease: 
H2: Hospitals in more dynamic markets will have a lower $\mathrm{RN}$ staffing intensity and a lower $\mathrm{RN}$ to non-RN ratio than hospitals in less dynamic markets.

Complexity represents the level of complex knowledge needed to understand the environment. ${ }^{27}$ It is indicated by the degree of market concentration and the level of homogeneity/heterogeneity in environmental elements. ${ }^{19,23}$ Complexity is also closely related to the information uncertainty perspective. The information uncertainty perspective suggests that an organization becomes more uncertain regarding the environment when the number of environmental factors that the focal organization should be considering making better decisions increases. If environmental constituents (ie, hospitals) increase, hospitals may face increasing uncertainty due to the increased number of factors to consider as the number of competitors increases. Meanwhile, resource dependence theory suggests that market competition is a large predictor of organizational strategies/actions. ${ }^{30}$ Hospitals in more competitive markets are more likely to make strategic moves to secure necessary resources while staying competitive.

To maintain control over necessary resources and to remain competitive in a highly competitive market, hospitals may consider changing their human capital structure (eg, increasing the proportion of RNs) to pursue a higher quality of care to be competitive, while reducing the number of LPNs to secure the financial resources needed to remain viable. Robinson commented that "hospitals compete on a nonprice rather than price basis," and that "dense hospital markets are the scene of more intense quality competition for physician affiliations and patient admissions than are monopolistic markets." 25 He suggested that staffing inputs are the main targets in the nonprice competition, and that hospitals in markets with higher competition are likely to maintain higher ratios of nurses to beds and proportionally more RNs and fewer LPNs. $^{25}$ Therefore, this study posits that higher levels of complexity will be linked to more RNs per inpatient day and a higher RN proportion in hospitals:

H3: Hospitals in more complex markets will have a higher $\mathrm{RN}$ staffing intensity and a higher $\mathrm{RN}$ to non-RN ratio than hospitals in less complex markets.

\section{Methods}

Our research is designed as a non-experimental, longitudinal study, using secondary data analysis. This study used longitudinal panel datasets from 2006 to 2010, drawn from the American Hospital Association (AHA) Annual Survey Database, the Area Health Resources Files (AHRF) of the US Department of Health and Human Services (HHS), the Case Mix Index File of the Centers for Medicare \& Medicaid Services (CMS), the Local Area Unemployment Statistics (LAUS) of the Bureau of Labor Statistics, and the Magnet Hospital status data. The AHA Annual Survey database provides data regarding hospitals' organizational characteristics, utilization, staffing, and expenses. The AHRF database includes county-level data with respect to health facilities, health professions, resource scarcity measures, health statuses, economic activities, health training programs, and socioeconomic and environmental characteristics. Previous healthcare research that investigated nurse staffing in hospitals has often utilized both the AHA and AHRF databases. ${ }^{15,29,31-}$

33 The Case Mix Index File contains the case mix index (CMI) for discharges in hospitals, representing the average diagnosis-related group (DRG) relative weight for the hospitals. The CMI is computed by adding the DRG weights for all Medicare discharges divided by the number of discharges, for both transfer-adjusted and unadjusted cases. The LAUS data include information regarding monthly estimates of total employment and unemployment for different geographical levels (eg, metropolitan areas, cities, census regions and divisions, as well as counties). Lastly, data indicating hospitals' Magnet Hospital status are collected manually from the American Nurses Credentialing Center website (https://www.nursingworld. org/organizational-programs/magnet/find-a-magnetorganization/).

The unit of analysis is hospital-years. The sampling frame consists of US general and acute care hospitals that are not owned by the federal government. After merging the datasets, our final sample includes 4,206, 4,289, 4,227, 4,276 , and 4,266 hospitals each year, from 2006 to 2010, respectively. The panel dataset included 21,264 hospitalyears for analysis. All data accessed complied with relevant data protection and privacy regulation.

\section{Variables}

RN staffing is the outcome of interest in this study. Two dependent variables were used to measure RN staffing in hospitals: RN staffing intensity (RN FTEs divided by 1,000 inpatient days); and $\mathrm{RN}$ to non-RN ratio ( $\mathrm{RN}$ FTEs divided by the sum of LPN and nursing aides FTEs) (see Table 1). To normalize the distribution, the 
Table I Summary of Variables

\begin{tabular}{|c|c|c|}
\hline Variable & Definition & $\begin{array}{l}\text { Data } \\
\text { Source }\end{array}$ \\
\hline \multicolumn{3}{|l|}{ Dependent Variable } \\
\hline \multicolumn{3}{|l|}{ RN Staffing } \\
\hline RN staffing intensity & RN FTEs/(Inpatient days/I,000) & AHA \\
\hline $\mathrm{RN}$ to non- $\mathrm{RN}$ ratio & RN FTEs/(LPN and nursing aides FTEs) & $\mathrm{AHA}$ \\
\hline \multicolumn{3}{|l|}{ Independent Variable } \\
\hline \multicolumn{3}{|l|}{ Environment Factors } \\
\hline \multicolumn{3}{|l|}{ Munificence } \\
\hline Per capita income & Mean income within county & AHRF \\
\hline Urban location & Location in urban areas ( $\mathrm{I}$ : yes, $0:$ no) & $\mathrm{AHA}$ \\
\hline Specialist resource & \# of physician specialists per 1,000 capita & AHRF \\
\hline \multicolumn{3}{|l|}{ Dynamism } \\
\hline $\begin{array}{l}\text { Medicare HMO } \\
\text { penetration }\end{array}$ & Medicare HMO enrollment as percent of total Medicare population in a county & AHRF \\
\hline $\begin{array}{l}\text { Change in unemployment } \\
\text { rate }\end{array}$ & Yearly change in county unemployment rate & LAUS \\
\hline \multicolumn{3}{|l|}{ Complexity } \\
\hline $\mathrm{HHI}$ & The sum of squared market share of all hospitals in HSA & AHA \\
\hline \multicolumn{3}{|l|}{ Control Variable } \\
\hline Bed size & The number of staffed inpatient beds & $\mathrm{AHA}$ \\
\hline System affiliation & $\begin{array}{l}\text { Status of a hospital's membership in multihospital systems } \\
\text { (I: system hospital, 0: non-system hospital) }\end{array}$ & $\mathrm{AHA}$ \\
\hline Ownership & $\begin{array}{l}\text { Status of a hospital as a for-profit, not-for-profit private, or public entity } \\
\text { (I: for-profit, 2: not-for-profit private, } 3 \text { : public) }\end{array}$ & $\mathrm{AHA}$ \\
\hline Teaching status & $\begin{array}{l}\text { Existence of approved medical residency programs, affiliation with medical school or COTH } \\
\text { membership } \\
(\mathrm{I}: \text { yes, } 0: \text { no) }\end{array}$ & AHA \\
\hline Occupancy rate & Total inpatient days/number of staffed beds $* 365$ & AHA \\
\hline Case mix index* & Level of complexity in Medicare cases & CMI File \\
\hline Magnet status & Magnet Hospital credentialing & Magnet \\
\hline & (I:yes, 0: no) & Hospital \\
\hline LPN staffing intensity & LPN FTEs/(Inpatient days/I,000) & AHA \\
\hline
\end{tabular}

Note: *Missing values were imputed by the Gaussian normal regression imputation method software (StataCorp., 20I3) because of the large number of missing cases in the CMI data $(28.4 \%){ }^{43}$

dependent variables were all transformed into the natural logarithm. In addition, LPN staffing intensity (LPN FTEs divided by 1,000 inpatient days) was used as a control variable for $\mathrm{RN}$ staffing intensity in a regression model.

Our independent variables include six variables that operationalize the various dimensions of the environment (ie, munificence, dynamism, and complexity). Munificence was measured by three county-level variables: per capita income, urban location, and specialist resources. Previous hospital-nurse staffing studies or other healthcare studies using resource dependence theory have used these variables as measures of munificence. ${ }^{10,12,15,29,31,34}$ Per capita income was defined as mean income within county. Urban location was measured based on the 2003 Rural/Urban Continuum Codes in the AHRF database. It was coded as a binary measure in which a value of " 1 " means an urban location, while a value of " 0 " indicates a rural location. The definition of specialist resources is the number of physician specialists per 1,000 capita. We also had included the primary care resource as a measure of munificence in the study model; however, it was dropped from the model because of its high correlation ( 0.89 correlation coefficient) with specialist resources over a typical threshold (0.8), which was close to the value for high correlation (0.9 and higher). ${ }^{35}$ 
Dynamism was measured by Medicare HMO penetration and changes in the unemployment rate. Previous healthcare research utilized Medicare HMO penetration and the change in the unemployment rate as measures of dynamism. ${ }^{9,10,12}$ Medicare HMO penetration was measured by Medicare HMO enrollment as a percentage of the total Medicare population in the county. Change in the unemployment rate was defined as the yearly change in the county unemployment rate.

Complexity was captured by the degree of competition in the local market. Previous hospital nurse staffing studies utilized the Herfindahl-Hirschman Index (HHI) as a market factor, while others explicitly used it as a measure of complexity. ${ }^{10,12,15,31,34}$ The HHI is a frequently used measure in the healthcare literature to represent market concentration: a high market concentration indicates low market competition. ${ }^{8,11,28}$ The HHI was computed by the sum of the squared market share of all hospitals in the health service area (HSA).

We used organizational factors as control variables. The size of beds has been frequently used in hospital nurse staffing studies. ${ }^{15,29,31,32,34}$ This paper defined bed size as the number of staffed beds. Additionally, we created a squared term of the bed size variable to determine whether any non-linear relationship could be detected in the regression analysis. System affiliation has often been used in the previous hospital nurse staffing research as well. ${ }^{15,32,34}$ Based on these studies, this paper defined system affiliation as the status of a hospital's membership in a multihospital system and operationalized this variable as a binary measure in which a value of "1" implies a system-affiliated status, while a value of " 0 " indicates a non-system affiliated status. Other organizational factors, such as ownership (for-profit, not-for-profit private, or public), teaching status (yes or no), occupancy rate (measured by the total number inpatient days divided by the number of staffed beds multiplied by 365), CMI, and Magnet status (yes or no) were controlled in all regressions models. These variables are hospital characteristics frequently used as either independent or control variables in hospital nurse staffing studies. ${ }^{15,31,32,34,36,37}$

\section{Data Analysis}

Univariate descriptive, paired $t$-test, and multivariate analysis with a random-effects linear regression model were conducted. The descriptive statistics were measured to examine the distributional properties of all variables, including frequencies, means, and standard deviations. Paired t-tests compared the mean values of the continuous variables between 2006 and 2010. Lastly, this paper used a randomeffects linear regression model to measure the influence of market conditions on RN staffing. In a longitudinal analysis, an ordinary least squares (OLS) analysis would provide biased estimates by using repeated observations per individual, as the observations are not independent. Fixed-effects or random-effects models can take account of such repetition and control for fixed or random individual differences. While the fixed-effects model produces unbiased coefficients by ruling out any unobserved factors (eg, individual differences), the model's "ruling out" provides no estimation of time-constant effects and poor estimates if there is little variation in the variables. In contrast, by its assumption of the unobserved heterogeneity, the random effects model can include time-invariant variables. The random-effects linear regression model was chosen because 1) the study model used some independent variables that can be characterized as time-invariant factors whose effects would be absorbed in the fixed-effects model, and because 2) the dependent variables are continuous. In addition, time and state fixed effects controlled for the effect of time in the panel data and inter-state differences, respectively. Finally, robust standard errors were estimated to control for inter-entity differences.

\section{Results}

Table 2 provides descriptive statistics for a total of 21,264 hospital-years. On average, the sample hospitals had 164 beds, with $56 \%$ occupancy, and had a CMI of 1.37. A majority of hospitals were non-teaching hospitals $(76.9 \%)$, non-Magnet hospitals $(95.5 \%)$, in urban settings $(67.5 \%)$, and with a not-for-profit private tax designation $(60.9 \%)$. Approximately $55 \%$ of sample hospitals were affiliated with a system. Sample hospitals had an average of 7.2 RN FTEs and 1.2 LPN FTEs per inpatient day and the number of RN FTEs was 2.6 times greater than the number of LPN and nursing aide FTEs, on average. The sample hospitals were located in counties whose population earned US $\$ 35,000$ per year, and whose HHI was 0.77 , on average. On average, these counties had 1.5 physician specialists per 1,000 population, and about $17 \%$ of those eligible for Medicare were enrolled in Medicare HMOs. The yearly change in the unemployment rate was $15 \%$, on average.

The results of the paired t-tests are presented in Table 3. Except for LPN staffing intensity and beds, there were statistically significant differences in the mean values of 
Table 2 Descriptive Statistics

\begin{tabular}{|c|c|c|c|}
\hline Variable & Hospital/Years & Mean/Frequency (\%) & SD \\
\hline \multicolumn{4}{|l|}{ Dependent Variables } \\
\hline RN staffing intensity & 21,264 & 7.22 & 4.05 \\
\hline $\mathrm{RN}$ to non- $\mathrm{RN}$ ratio & 20,856 & 2.67 & 1.64 \\
\hline \multicolumn{4}{|l|}{ Independent Variables } \\
\hline \multicolumn{4}{|l|}{ Environment factors } \\
\hline \multicolumn{4}{|l|}{ Munificence } \\
\hline Per capita income $(\$ 1,000)$ & 21,264 & 35.15 & 9.16 \\
\hline Specialist resources (per 1,000$)$ & 21,264 & 1.49 & 1.28 \\
\hline Urban location & 21,264 & & \\
\hline Urban & & $\mid 4,344(67.5 \%)$ & \\
\hline Rural & & $6,920(32.5 \%)$ & \\
\hline \multicolumn{4}{|l|}{ Dynamism } \\
\hline Medicare HMO penetration & 21,264 & 0.17 & 0.13 \\
\hline Change in unemployment rate & 21,264 & 0.15 & 0.28 \\
\hline \multicolumn{4}{|l|}{ Complexity } \\
\hline $\mathrm{HHI}$ & 21,264 & 0.77 & 0.32 \\
\hline \multicolumn{4}{|l|}{ Control variables } \\
\hline Bed & 21,264 & 164.00 & 164.93 \\
\hline System affiliation & 21,264 & & \\
\hline Affiliated & & II,737(55.2\%) & - \\
\hline Not-affiliated & & $9,527(44.8 \%)$ & - \\
\hline Ownership & 21,264 & & \\
\hline For-profit & & $3,401(16.0 \%)$ & - \\
\hline Not-for-profit, private & & $12,942(60.9 \%)$ & - \\
\hline Not-for-profit, public (non-federal) & & $4,921(23.1 \%)$ & - \\
\hline Teaching status & 21,264 & & \\
\hline Teaching hospital & & $4,918(23.1 \%)$ & - \\
\hline Non-teaching hospital & & $16,346(76.9 \%)$ & - \\
\hline Occupancy rate & 21,264 & 0.56 & 0.19 \\
\hline CMI & 15,216 & 1.37 & 0.27 \\
\hline Magnet hospital status & 21,264 & & \\
\hline Magnet hospital & & $950(4.5 \%)$ & - \\
\hline Non-magnet hospital & & $20,314(95.5 \%)$ & - \\
\hline LPN staffing intensity & 21,264 & 1.18 & 1.36 \\
\hline
\end{tabular}

variables between 2006 and 2010. Compared with 2006, hospitals tended to have a higher RN staffing intensity and a higher $\mathrm{RN}$ to non-RN ratio in 2010, while they had lower occupancy rates and higher CMIs in 2010. With respect to market condition variables, compared with 2006, the environments in which those hospitals were located had higher per capital incomes, higher specialist resources, higher Medicare HMO penetrations and changes in the unemployment rate, and higher HHIs in 2010. In summation, compared with 2006, hospitals served sicker patients, had lower occupancies, had increased levels of RN staffing, and operated in more munificent and dynamic, but slightly less complex (ie, less competitive), environments in 2010.
The results of two random-effects regression analyses showed that several variables measuring munificence, dynamism, and complexity were significantly associated with each of the two staffing measures (see Table 4). We found strong support for Hypothesis 1, which postulated a positive relationship of munificence with $\mathrm{RN}$ staffing intensity and $\mathrm{RN}$ to non-RN ratio. When computing the exponential coefficient, an additional $\$ 1,000$ per capita income was associated with a $0.3 \%$ increase in $\mathrm{RN}$ staffing intensity, while an additional specialist per 1,000 population was related to an increase of $1.8 \%$ in $\mathrm{RN}$ staffing intensity. In addition, urban hospitals had approximately a $16.1 \%$ higher $\mathrm{RN}$ staffing intensity than rural hospitals. 
Table 3 Mean Difference of Variables Between 2006 and 2010

\begin{tabular}{|c|c|c|c|c|c|}
\hline \multirow[b]{2}{*}{ Variable } & \multicolumn{2}{|l|}{2006} & \multicolumn{2}{|l|}{2010} & \multirow[b]{2}{*}{ P-value } \\
\hline & Mean & SD & Mean & SD & \\
\hline RN staffing intensity & 6.544 & 3.550 & 7.956 & 4.362 & 0.000 \\
\hline $\mathrm{RN}$ to non- $\mathrm{RN}$ ratio & 2.508 & $\mathrm{I} .562$ & 2.858 & 1.698 & 0.000 \\
\hline Per capita incomes $(\$ 1,000)$ & 32.375 & 8.865 & 36.492 & 8.600 & 0.000 \\
\hline Medicare $\mathrm{HMO}$ penetration & 0.140 & 0.123 & 0.205 & 0.137 & 0.000 \\
\hline Change in unemployment rate & -0.092 & 0.087 & 0.033 & 0.088 & 0.000 \\
\hline $\mathrm{HHI}$ & 0.780 & 0.315 & 0.782 & 0.312 & 0.040 \\
\hline Bed & 167.168 & 163.207 & 168.120 & 168.295 & 0.157 \\
\hline Occupancy rate & 0.575 & 0.184 & 0.543 & 0.185 & 0.000 \\
\hline CMI & 1.347 & 0.254 & 1.401 & $0.27 \mathrm{I}$ & 0.000 \\
\hline
\end{tabular}

Table 4 The Relationship Between Contextual Factors and RN Staffing Levels

\begin{tabular}{|c|c|c|c|c|}
\hline & \multicolumn{2}{|c|}{$\begin{array}{l}\text { RN Staffing } \\
\text { Intensity }\end{array}$} & \multicolumn{2}{|c|}{$\begin{array}{l}\text { RN to Non-RN } \\
\text { Ratio }\end{array}$} \\
\hline & Coef. & $\begin{array}{l}\text { Std. } \\
\text { Err. }\end{array}$ & Coef. & $\begin{array}{l}\text { Std. } \\
\text { Err. }\end{array}$ \\
\hline Per capita income & $0.003 * * *$ & 0.000 & $0.004 * * *$ & 0.001 \\
\hline Urban location & $0.149 * * *$ & 0.011 & $0.176 * * *$ & 0.015 \\
\hline Specialist resources & $0.018^{* * * *}$ & 0.004 & $0.011^{*}$ & 0.006 \\
\hline $\begin{array}{l}\text { Medicare HMO } \\
\text { penetration }\end{array}$ & 0.022 & 0.030 & $0.215^{* * *}$ & 0.047 \\
\hline $\begin{array}{l}\text { Change in } \\
\text { unemployment rate }\end{array}$ & 0.002 & 0.006 & 0.005 & 0.012 \\
\hline $\mathrm{HHI}$ & $-0.05 \mathrm{I} * * *$ & 0.012 & $-0.045^{*}$ & 0.017 \\
\hline Bed & $-0.002 * * *$ & 0.000 & $0.000 * * *$ & 0.000 \\
\hline Square bed & $0.000 * * *$ & 0.000 & $-0.000 * * *$ & 0.000 \\
\hline System affiliation & $0.013 *$ & 0.006 & $0.058^{* * *}$ & 0.009 \\
\hline \multicolumn{5}{|l|}{$\begin{array}{l}\text { Ownership (reference: } \\
\text { for-profit) }\end{array}$} \\
\hline Not-for-profit private & $0.043 * * *$ & 0.010 & $0.051 * * *$ & 0.014 \\
\hline Public & -0.008 & 0.013 & $-0.078 * * *$ & 0.018 \\
\hline Teaching status & $0.074 * * *$ & 0.007 & $0.019 *$ & 0.010 \\
\hline Occupancy rate & $-0.88 I^{* * *}$ & 0.022 & $-0.252 * * *$ & 0.025 \\
\hline CMI & $0.214 * * *$ & 0.014 & $0.212^{* * *}$ & 0.024 \\
\hline Magnet hospital status & $0.059 * * *$ & 0.008 & $0.041^{*}$ & 0.016 \\
\hline LPN staffing intensity & $0.052^{* * *}$ & 0.004 & - & - \\
\hline \multicolumn{5}{|l|}{ Year (reference: 2006) } \\
\hline 2007 & $0.046 * * *$ & 0.002 & $0.059 * * *$ & 0.005 \\
\hline 2008 & $0.087^{* * *}$ & 0.004 & $0.100 * * *$ & 0.007 \\
\hline 2009 & $0.107 * * *$ & 0.005 & $0.090 * * *$ & 0.010 \\
\hline 2010 & $0.070 * * *$ & 0.004 & $0.118 * * *$ & 0.007 \\
\hline $\mathrm{F}$ & \multicolumn{2}{|l|}{$99.70 * * *$} & \multicolumn{2}{|l|}{$75.34 * * *$} \\
\hline
\end{tabular}

Notes: ${ }^{\mathrm{p}}<0.05 ;{ }^{* * *} \mathrm{p}<0.001$.
In the meantime, an additional $\$ 1,000$ per capita income and an additional specialist per 1,000 population were associated with a $0.4 \%$ and a $1.1 \%$ increase in $\mathrm{RN}$ to non$\mathrm{RN}$ ratio, respectively, while urban hospitals had about a $19.3 \%$ higher ratio than rural hospitals.

Hypothesis 2 argued for a negative relationship of dynamism with $\mathrm{RN}$ staffing intensity and $\mathrm{RN}$ to non-RN ratio. There was no statistically significant finding for RN staffing intensity. Opposite to our expectation, however, we found a positive relationship between dynamism and $\mathrm{RN}$ to non-RN ratio; a $1 \%$ increase of Medicare HMO penetration was related to a $24 \%$ increase in $\mathrm{RN}$ to non$\mathrm{RN}$ ratio. Therefore, our results did not support hypothesis 2.

Our analysis provided support for hypothesis 3 that theorized a positive relationship of complexity with $\mathrm{RN}$ staffing intensity and $\mathrm{RN}$ to non-RN ratio. We found that a $1 \%$ increase in $\mathrm{HHI}$ (a negative sign of competition) was related to a 5\% decrease in $\mathrm{RN}$ staffing intensity and a $4.4 \%$ decrease in $\mathrm{RN}$ to non- $\mathrm{RN}$ ratio.

With respect to the control variables, we found evidence of non-linear relationships, as shown by the opposite-directional relationships of the number of beds and the squared term of the number of beds with $\mathrm{RN}$ staffing intensity and $\mathrm{RN}$ to non-RN ratio. In addition, not-forprofit hospitals had a higher RN staffing intensity and $\mathrm{RN}$ to non-RN ratio than for-profit hospitals, while forprofit hospitals had a higher $\mathrm{RN}$ to non-RN ratio than public hospitals. We also found that teaching hospitals had a higher RN staffing intensity and RN to non-RN ratio than non-teaching hospitals. Regarding the CMI, we found that $\mathrm{RN}$ staffing intensity and $\mathrm{RN}$ to non-RN ratio 
increased as the CMI increased. Our results also showed that Magnet hospitals had a higher RN staffing intensity and a higher $\mathrm{RN}$ to non-RN ratio than non-Magnet hospitals. For the occupancy rate, both staffing measures were negatively influenced by the occupancy rate.

\section{Discussion}

Overall, the findings of this study indicate that hospitals in different external environments vary in the levels of $\mathrm{RN}$ staffing intensity and $\mathrm{RN}$ to non- $\mathrm{RN}$ ratio. We found all measures of munificence, as well as one measure of each dynamism and complexity, were significant predictors of using greater numbers of RNs per 1,000 inpatient days, as well as the relative ratio of RNs to the less skilled nursing workforce in hospitals. Our findings suggest that environmental munificence is a significant predictor of hospitals' decisions regarding the levels of $\mathrm{RN}$ staffing. In our results, hospitals had a higher $\mathrm{RN}$ staffing intensity and $\mathrm{RN}$ to non-RN ratio when the environment was more munificent. Our findings suggest that hospitals in communities with lower per capita incomes are likely to have fewer RNs, which may give rise to a question regarding the proper levels of quality of patient care in these areas. In addition, in rural areas, which are often characterized by lower access to care, hospitals are likely to have a lower RN staffing intensity than urban hospitals. Moreover, our findings also suggest that where specialist resources in markets decrease, so do RNs in hospitals. These findings suggest that RN resources are likely to be low in communities that may already suffer from a lower access of care.

In this study, we found no significant relationship between Medicare HMO penetration, which is characterized by increasing environmental dynamism, and RN staffing intensity; however, it was positively associated with $\mathrm{RN}$ to non-RN ratio. Collectively, our findings suggest that hospitals in more dynamic environments may have a higher $\mathrm{RN}$ to non-RN ratio than hospitals in less dynamic environments, probably because of the negative impact of the dynamic environment on the number of nonRN staffing intensity, not because of any changes in $\mathrm{RN}$ staffing intensity associated with the environmental dynamism. This suggestion is understandable based on the contentions of Zhao et al and Unruh who stated that due to quality of care concerns, hospitals tend to keep core staffs and reduce less skilled nurses more when a reduction in nursing staffs is necessary, which increased $\mathrm{RN}$ to non$\mathrm{RN}$ ratio as in our findings. ${ }^{15,24}$ Our findings are similar to those of a unit-level study by Spetz et al who found a negative relationship between HMO penetration and LPN hours but no significant relationship between HMO penetration and $\mathrm{RN}$ hours, as well as to those of a hospitallevel study by Spetz et al who found a negative relationship of HMO penetration with LPN FTEs and LPN skill mix. $^{14,38}$

Consistent with our hypothesis 3, complexity was significantly associated with RN staffing in hospitals. Our findings suggest that higher competition, which is characterized by increasing environmental complexity, is associated with a higher RN staffing intensity and a higher RN to non-RN ratio in hospitals. Hospital markets are often characterized as dense markets that give rise to intense competition for physicians and patients based, not on price, but on nonprice (eg, quality). Thus, one of the strategies that may make a hospital more competitive in such markets is to increase the quality of patient care, and a general course of action to hospitals may be to have proportionally more RNs and fewer non-RN nurses, as a higher skill mix can be highly visible to those physicians and patients for which the hospitals compete. ${ }^{25}$ Our findings confirmed that the theory of nonprice competition applies to the competitive hospital market, and are also consistent with the findings of the previous cross-sectional unit-level study and hospital-level study. ${ }^{25,39}$

With respect to organizational factors (control variables), we found that both bed size and system affiliation were significant predictors of RN staffing. First, we found a non-linear relationship of bed size with $\mathrm{RN}$ staffing intensity and $\mathrm{RN}$ to non-RN ratio. Interpreting bed size and the squared term of bed size together, our findings provide evidence of economies of scale, such that the number of RNs required per bed decreases as the number of beds increases up to a certain number of beds in hospitals due to increased production efficiency; however, once the number of beds becomes too large to be covered by the given number of RNs, the number of RNs required per bed increases again. In addition, our finding of a relationship between bed size and $\mathrm{RN}$ to non-RN ratio suggests that the demand for RNs over LPNs and nursing aides increases sharply as the number of beds in hospitals increases up to a certain number of beds but decreases as the number of beds increases beyond a certain bed size. This finding is not consistent with two previous studies; however, they used different staffing measures, such as the number of RNs or RN hours. ${ }^{25,40}$ As expected, we found that systemmember hospitals had a higher RN staffing intensity and $\mathrm{RN}$ to non-RN ratio than independent hospitals. It is 
possible that greater resource availability for the members of a multihospital system enabled using more RNs per inpatient day and proportionately more RNs over LPNs and nursing aides in the member hospitals. Our finding is consistent with the results of a previous cross-sectional study. ${ }^{41}$

We found that other control variables, eg, ownership, teaching status, occupancy rate, CMI, and Magnet status, all significantly influenced RN staffing. As expected, forprofit hospitals were found to be more under-staffed than not-for-profit private hospitals. Regarding our finding with respect to the higher $\mathrm{RN}$ to non- $\mathrm{RN}$ ratio in for-profit hospitals than in public hospitals, Robinson provides some hints that our data may pick up the influence of rural county hospitals with limited budgets and midranged case mix. ${ }^{25}$ Meanwhile, teaching hospitals had a higher RN staffing intensity and a higher RN to non$\mathrm{RN}$ ratio than non-teaching hospitals probably due to their needs for more skilled staff to serve sicker people as well as to manage more technology, which is consistent with the results of Robinson's study. ${ }^{25,42}$ Given that a higher CMI requires more skilled nurses and that Magnet status represents better working conditions for RNs, most of our findings on the relationship between CMI and Magnet status and RN staffing measures were understandable. Regarding the occupancy rate, it seems probable that the occupancy rate influences the related staffing measures similarly as bed size does (ie, economies of scale).

This study highlights the importance of market conditions in RN staffing levels in hospitals. Using a national sample of general, non-federal, short-term acute care hospitals, the generalizability of our findings has been enhanced at the hospital level. However, our findings must be interpreted with respect to several limitations. First, we used hospital-level data that do not provide information on unit-level staffing. To be exact, levels of staffing in units of hospitals should be compared to capture the true influence of market conditions on RN staffing in hospitals. If a hospital maintains sufficient RN staffing in highly competitive and profitable core service lines (eg, cardiac services) but relatively lower levels of RN staffing in most other lines, hospital-level studies may not capture the actual influence of market conditions on RN staffing. Second, we were unable to include some important variables, such as market wage levels, in the study model. Therefore, the effect of market conditions might be over or underestimated. Lastly, most of the market condition variables were measured at the county level. Defining a county as the market for hospitals may not be precise because the mobility of major input sources (ie, patients and nurses) of the hospital is not restricted to the county in which the hospital operates. ${ }^{39}$

\section{Conclusion}

Considering the significant influence of RN staffing on healthcare quality, as well as the fact that the wages and benefits of nurses constitute a substantial portion of overall hospital costs, we cannot overemphasize the importance of providing sufficient RN staff in hospitals. Central to this paper has been the questions of which market conditions influence RN staffing in hospitals, as well as their means of influence. This paper provides strong evidence that several external environmental conditions predict RN staffing in hospitals. From our findings, some implications may be drawn.

Given that certain staffing decisions are more suitable in certain market conditions, our findings suggest that nurse managers, chief nurses, and chief executive officers should consider fitting their RN staffing strategy to the external operating environment. They should also take environmental conditions into consideration when making staffing decisions. For example, our findings suggest that information about any noticeable changes anticipated in the markets, in terms of the economic conditions, the supply of the physician population, managed care penetration, and/or market concentration levels may be useful for nurse managers to evaluate their staffing plans.

Our findings also have a policy implication regarding the supply of RNs. In addition to direct governmental interventions, modulating environmental forces that influence RN staffing in hospitals may improve the levels of the RN supply in communities whose staffing levels are socially undesirable. Our findings suggest that governmental initiatives designed to improve the spatial distribution of physicians must have its own aimed effects but may also indirectly influence the levels of $\mathrm{RN}$ staffing in hospitals, thereby inducing improved supply of RNs in the focal communities. It is important to understand that local hospitals deliver healthcare services to community members and that their levels of $\mathrm{RN}$ staffing reflect the supply of RNs in the community. If adequate levels of nurse staffing in communities are of interest, factors determining nurse staffing in the hospitals operating in those communities should be well understood. 


\section{Ethical Statement}

Institutional Review Board (IRB) approval was waived since this study did not get involved with human subjects.

\section{Disclosure}

Professor Robert Weech-Maldonado reports grants from the Agency for Healthcare Research \& Quality, National Science Foundation, National Institute on Aging, and RAND/Centers for Medicare and Medicaid Services, outside the submitted work. The authors report no other conflicts of interest in this work.

\section{References}

1. Meyer AD. What is strategy's distinctive competence. J Manage. 1991;17(4):821-833. doi:10.1177/014920639101700413

2. Delaney JT, Huselid MA. The impact of human resource management practices on perceptions of organizational performance. Acad Manage J. 1996;39(4):949-969. doi:10.5465/256718

3. Huselid MA. The impact of human resource management practices on turnover, productivity, and corporate financial performance. Acad Manage J. 1995;38(3):635-672. doi:10.5465/256741

4. Phillips J, Gully SM. Strategic Staffing. Pearson Prentice Hall; 2009.

5. Lawrence PR, Lorsch JW. Organization and Environment; Managing Differentiation and Integration. Boston: Division of Research, Graduate School of Business Administration, Harvard University; 1967.

6. Thompson JD. Organizations in Action; Social Science Bases of Administrative Theory. McGraw-Hill: New York; 1967.

7. Hsieh HM, Clement DG, Bazzoli GJ. Impacts of market and organizational characteristics on hospital efficiency and uncompensated care. Health Care Manage Rev. 2010;35(1):77-87. doi:10.1097/ HMR.0b013e3181c09956

8. Kazley AS, Ozcan YA. Organizational and environmental determinants of hospital EMR adoption: a national study. J Med Syst. 2007;31(5):375-384. doi:10.1007/s10916-007-9079-7

9. Menachemi N, Mazurenko O, Kazley AS, Diana ML, Ford EW. Market factors and electronic medical record adoption in medical practices. Health Care Manage Rev. 2012;37(1):14-22. doi:10.1097/ HMR.0b013e3182352562

10. Menachemi N, Shin DY, Ford EW, Yu F. Environmental factors and health information technology management strategy. Health Care Manage Rev. 2011;36(3):275-285. doi:10.1097/HMR.0b013e3182048e7e

11. Trinh HQ, O'Connor SJ. Helpful or harmful? The impact of strategic change on the performance of U.S. urban hospitals. Health Serv Res. 2002;37(1):143-169. doi:10.1111/1475-6773.99208

12. Zinn JS, Proenca J, Rosko MD. Organizational and environmental factors in hospital alliance membership and contract management: a resource-dependence perspective. Hosp Health Serv Adm. 1997;42 (1):67-86.

13. Blegen MA, Vaughn T, Vojir CP. Nurse staffing levels: impact of organizational characteristics and registered nurse supply. Health Serv Res. 2008;43(1 Pt 1):154-173. doi:10.1111/j.14756773.2007.00749.x

14. Spetz J, Dyer WT, Chapman S, Seago JA. Hospital demand for licensed practical nurses. West J Nurs Res. 2006;28(6):726-739. doi:10.1177/0193945906286811

15. Zhao M, Bazzoli GJ, Clement JP, Lindrooth RC, Nolin JM, Chukmaitov AS. Hospital staffing decisions: does financial performance matter? Inquiry. 2008;45(3):293-307. doi:10.5034/ inquiryjrnl_45.03.293
16. Duncan RB. Characteristics of organizational environments and perceived environmental uncertainties. Adm Sci Q. 1972;17(3):313-327. doi: $10.2307 / 2392145$

17. Barnard CI. The Functions of the Executive. Cambridge, Mass: Harvard University Press; 1938.

18. Pfeffer J, Salancik GR. The External Control of Organizations: A Resource Dependence Perspective. New York: Harper \& Row; 1978.

19. Tan JJ, Litschert RJ. Environment-strategy relationship and its performance implications: an empirical study of the Chinese electronics industry. Strateg Manag J. 1994;15(1):1-20. doi:10.1002/ smj.4250150102

20. Kreiser P, Marino L. Analyzing the historical development of the environmental uncertainty construct. Manag Decis. 2002;40 (9):895-905. doi:10.1108/00251740210441090

21. Spetz J, Donaldson N, Aydin C, Brown DS. How many nurses per patient? Measurements of nurse staffing in health services research. Health Serv Res. 2008;43(5 Pt 1):1674-1692. doi:10.1111/j.14756773.2008.00850.x

22. Unruh L. Nurse staffing and patient, nurse, and financial outcomes. Am J Nurs. 2008;108(1):62-71; quiz 72. doi:10.1097/01. NAJ.0000305132.33841.92

23. Dess GG, Beard DW. Dimensions of organizational task environments. Adm Sci Q. 1984;29(1):52-73. doi:10.2307/2393080

24. Unruh L. The effect of LPN reductions on RN patient load. J Nurs Adm. 2003;33(4):201-208. doi:10.1097/00005110-200304000-0004

25. Robinson JC. Market structure, employment, and skill mix in the hospital industry. South Econ J. 1988;55(2):315-325. doi:10.2307/ 1059105

26. Miller D. The structural and environmental correlates of business strategy. Strateg Manag J. 1987;8(1):55-76. doi:10.1002/ smj.4250080106

27. Sharfman MP, Dean JW. Conceptualizing and measuring the organizational environment: a multidimensional approach. J Manage. 1991;17(4):681-700. doi:10.1177/014920639101700403

28. Banaszak-Holl J, Zinn JS, Mor V. The impact of market and organizational characteristics on nursing care facility service innovation: a resource dependency perspective. Health Serv Res. 1996;31 (1):97-117.

29. Bloom JR, Alexander JA, Nuchols BA. Nurse staffing patterns and hospital efficiency in the United States. Soc Sci Med. 1997;44 (2):147-155. doi:10.1016/S0277-9536(96)00063-9

30. Lucas JA, Avi-Itzhak T, Robinson JP, Morris CG, Koren MJ, Reinhard SC. Continuous quality improvement as an innovation: which nursing facilities adopt it? Gerontologist. 2005;45(1):68-77. doi:10.1093/geront/45.1.68

31. Everhart D, Neff D, Al-Amin M, Nogle J, Weech-Maldonado R. The effects of nurse staffing on hospital financial performance: competitive versus less competitive markets. Health Care Manage Rev. 2013;38(2):146-155. doi:10.1097/HMR.0b013e318257292b

32. Mark BA, Harless DW, McCue M. The impact of HMO penetration on the relationship between nurse staffing and quality. Health Econ. 2005;14(7):737-753. doi:10.1002/hec.988

33. McCue M, Clement J, Hoerger T. The association of ownership and system affiliation with the financial performance of inpatient psychiatric hospitals. Inquiry. 1993;30(3):306-317.

34. McCue M, Mark BA, Harless DW. Nurse staffing, quality, and financial performance. J Health Care Finance. 2003;29(4):54-76.

35. Hair JF, Black WC, Babin BJ, Anderson RE. Multivariate Data Analysis. 7th ed. Upper Saddle River, NJ: Prentice Hall; 2013.

36. Bacon CT, Hughes LC, Mark BA. Organizational influences on patient perceptions of symptom management. Res Nurs Health. 2009;32(3):321-334. doi:10.1002/nur.20319

37. Bacon CT, Mark B. Organizational effects on patient satisfaction in hospital medical-surgical units. J Nurs Adm. 2009;39(5):220-227. doi:10.1097/NNA.0b013e3181a23d3f 
38. Spetz J. The effects of managed care and prospective payment on the demand for hospital nurses: evidence from California. Health Serv Res. 1999;34(5 Pt 1):993-1010.

39. Mark BA, Salyer J, Wan TT. Market, hospital, and nursing unit characteristics as predictors of nursing unit skill mix: a contextual analysis. J Nurs Adm. 2000;30(11):552-560. doi:10.1097/00005110200011000-00011

40. Sloan FA, Elnicki RA. Nurse staffing in hospitals: a microeconometric analysis. Ind Relat (Berkeley). 1980;19 (1):15-33. doi:10.1111/j.1468-232X.1980.tb00150.x
41. Becker ER, Foster RW. Organizational determinants of nurse staffing patterns. Nurs Econ. 1998;6(2):71-75.

42. Seago JA, Spetz J, Mitchell S. Nurse staffing and hospital ownership in California. J Nurs Adm. 2004;34(5):228-237. doi:10.1097/ 00005110-200405000-00006

43. StataCorp. Stata: Release 13. Statistical Software. College Station, TX: StataCorp LP; 2013.

\section{Publish your work in this journal}

Risk Management and Healthcare Policy is an international, peerreviewed, open access journal focusing on all aspects of public health, policy, and preventative measures to promote good health and improve morbidity and mortality in the population. The journal welcomes submitted papers covering original research, basic science, clinical \& epidemiological studies, reviews and evaluations, guidelines, expert opinion and commentary, case reports and extended reports. The manuscript management system is completely online and includes a very quick and fair peer-review system, which is all easy to use. Visit http://www.dovepress.com/testimonials.php to read real quotes from published authors. 